Preserving pre-1972 sound recordings The Council on Library and Information Resources (CLIR) and the Library of Congress copublished "Copyright and Related Issues Relevant to Digital Preservation and Dissemination of Unpublished Pre-1972 Sound Recordings by Libraries and Archives."

The 85-page report, written by June M. Besek of Columbia Law School, provides guidance for cultural institutions that wish to digitize and distribute pre-1972 unpublished sound recordings. Unpublished recordings were not originally made for online distribution to the public with rights holders' permission, such as private recordings of live musical performances, interviews done for field research, oral history, or news gathering. Rights attached to pre-1972 unpublished recordings are different from the rights attached to pre-1972 commercial recordings and all post-1972 recordings.

Because the laws governing these rights are very complex and there is not much precedent in case law, there are no hard and fast guidelines. Instead, Besek poses nine scenarios and a series of questions to evaluate if various distribution activities could be the basis for a legal claim.

The report is available free of charge at www.clir.org/pubs/abstract/pub144abst. html. Print copies are also available for $\$ 25$ each and may be ordered at the same URL.

\section{IASA TC04}

The International Association of Sound and Audiovisual Archives (IASA) published the second edition of the IASA Technical Committee Standards, Recommended Practices and Strategies, IASA-TC04, Guidelines on the Production and Preservation of Digital Audio Objects. The new edition of the de facto standard for audio preservation was substantially

Jane Hedberg is senior preservation program officer at Harvard University Library, e-mail: jane_ hedberg@harvard.edu; fax: (617) 496-8344 revised and updated to include information about creating metadata, structure of OAIS compliant digital repositories, small scale storage solutions, and out-sourcing.

The 150-page publication costs 15 Euros, plus 8 Euros postage, and is available from IASA at www.iasa-web.org/special_publications.asp.

\section{Preservation of sound recordings}

The Association for Recorded Sound Collections Technical Committee (ARSC TC) has published "Preservation of Archival Sound Recordings, version 1." The ninepage statement endorses IASA documents TC03 and TC04 and supports the principle of preservation by transfer to an archival digital format. It covers general principles and guidelines, metadata-related data and other information, digital copies, transfer from analog masters, transfer from digital originals, and storing the digital files. ARSC TC also has published a five-page annotated bibliography, "Essential Resources for Audio Preservation," which describes the 16 documents it deems necessary for successful audio preservation.

Both documents are available free of charge at www.arsc-audio.org /technical-committee.html.

\section{Graphics Atlas}

The Image Permanence Institute (IPI) at the Rochester Institute of Technology is upgrading the print identification Web site originally called Digital Sample Book and renaming it Graphics Atlas. There is a print identification application that guides users through samples of prints as they appear under magnification. There is an object explorer application that allows browsing and comparison of different processes through images of various print characteristics. There are also histories of printing technologies.

The URL for the Web site is www. graphicsatlas.org. $\geq$ 